\title{
Emergency Physicians Awareness of Computed Tomography Indication in Traumatic Brain Injury: A Questionnaire-Based Study
}

\author{
Hassan Bukhari \\ Department of Surgery, Medical College, Umm Al-Qura University, Makkah, KSA \\ Email:drhb2000@yahoo.com
}

How to cite this paper: Bukhari, H. (2017) Emergency Physicians Awareness of Computed Tomography Indication in Traumatic Brain Injury: A Questionnaire-Based Study. Open Journal of Emergency Medicine, 5, 93-101.

https://doi.org/10.4236/ojem.2017.53009

Received: June 25, 2017

Accepted: July 28, 2017

Published: July 31, 2017

Copyright $\odot 2017$ by author and Scientific Research Publishing Inc. This work is licensed under the Creative Commons Attribution International License (CC BY 4.0).

http://creativecommons.org/licenses/by/4.0/

\begin{abstract}
Minor head injury (MHT) is one of the most common causes of all trauma admissions and it is still controversial to manage adequately. Although the incidence of clinically significant traumatic brain injury is low in this group, the consequences of missing clinically important problem are potentially life threatening. Early diagnosis of intracranial hematoma by computed tomography scan (CT) followed by early surgery is very important in the treatment of such patients. Thus, there has been a tendency to use high levels of diagnostic imaging in these conditions. There are many decision rules for the use of computed tomography (CT) for patients with minor head injury. This survey is to determine the awareness and utilization rates of these head CT rules among our emergency physicians (EP). Questionnaire was randomly sent to EPs from different ministry of health hospitals in Makkah. Our participants were asked about their awareness of such rules and their applications in their careers. Data were collected and analyzed by SPSS V16.0. The awareness and utilization rate of clinical decision rules among 91 ER physicians who responded were $54.4 \%$ and $42.2 \%$ respectively. The barriers to utilize such rules were the working environment and increased chances of getting lawsuits, which were $55.4 \%$ and $61.7 \%$ respectively. $91.1 \%$ of those physicians would like to receive guidance on how to apply such rules in their daily practices. There is a misunderstanding of the definition of minor head injury, despite the high number of head traumas, which led to request more CT scan. This will be a burden on the healthcare system and will lead to more radiation exposure. More educations regarding head CT rules will result in better utilizing of our resources and reduction in radiation risks.
\end{abstract}

\section{Keywords}

Minor Head Injury, Head CT Scan, Canadian CT Head Rule 


\section{Introduction}

An estimated 1.7 million people sustain a Traumatic Brain Injury (TBI) annually are seen in the United States' emergency rooms and $80 \%$ of them are classified as minimal or minor head injury where they are treated and released from an emergency department [1]. TBI is defined as a patient with a history of loss of consciousness, amnesia, or disorientation and a Glasgow Coma Scale (GCS) score of 13 - 15 [2]. Most patients with minimal head injuries who are not suffered from the mentioned symptoms are rarely requiring admission to hospital and can be discharged home [2]. However, there are $10 \%$ of those patients who will develop deterioration in their conditions by intracranial hematoma and only $1 \%$ will require neurosurgical intervention [3]. Therefore, an early diagnosis of intracranial hematoma by Computed tomography (CT) and early interventions in such patients are critical and important [2]. Computed tomography (CT) scan is an essential diagnostic tool in Emergency room due to its easy accessibilities with high accurate diagnostic approach. Moreover, CT scan is an integral rule to triage and manage patients with traumatic head injury because the consequences of missing a clinically important problem are potentially life threatening. Therefore, there is an increase in the number of CT scans requested at an astonishing rate by emergency physicians (ERs) more than any other department. For example, in 10 large Canadian hospitals, the use of CT scan has increased 165\%, from $30 \%$ to $80 \%$, especially for minor head injury patients [1]-[9]. Routine scanning results in increased in radiation exposure, and in large health care expenditures, especially when $90 \%$ of CT scans are negative for clinically important brain injury. So, reliance on clinical judgment could reduce CT use, but the cost will be missing in $20 \%$ of patients with intracranial injury [5] [8] [9]. Furthermore, studies and articles which have strongly suggested that all patients with minor head injury should undergo CT scan; it would eventually leads to a greater than $300 \%$ increase in the use of CT scan for Canadian and European patients with minor head injury [2]. Under these circumstances, the use of CT scan for minor head injury should be justified. Substantial potential for improving the efficiency of managing minor head trauma appears possible through the applications of clinical decision rules. A clinical decision rule is derived from original research and is defined as a decision making tool that incorporates 3 or more variables from the history, examination, or simple tests [9]. Several clinical decision rules are developed such as Canadian CT Head Rule (CCHR) "Figure 1", New Orleans CT Head Criteria (NOCC) "Figure 2" and guidelines from the National Institute for Clinical Excellence (NICE) [9]. This study aims to measure the emergency physicians' awareness toward indications of CT scanning in TBI according to CCHR and/or NOC by using a designed questionnaire with a short clinical scenario.

\section{Materials and Methods}

This cross-sectional study was conducted at king Abdul-Aziz Hospital, Hera 
Computed tomography is only required for patients with minor head injury with any 1 of the following findings: Patients with minor head injury who present with a Glasgow Coma Scale score of 13 to 15 after witnessed loss of consciousness, amnesia or confusion.

High Risk for Neurosurgical Intervention

1. Glasgow Coma Scale score lower than 15 at 2 hours after injury

2. Suspected open or depressed skull fracture

3. Any sign of basal skull fracture $\dagger$

4. Two or more episodes of vomiting

5. 65 years or older

Medium Risk for Brain Injury Detection by Computed Tomographic Imaging

6. Amnesia before impact of 30 or more minutes

7. Dangerous mechanism $\ddagger$

*The rule is not applicable if the patient did not experience a trauma, has a Glasgow

Coma

Scale score lower than 13 , is younger than 16 years, is taking warfarin or has a bleeding disorder,

or has an obvious open skull fracture.

†Signs of basal skull fracture include hemotympanum, raccoon eyes, cerebrospinal fluid: otorrhea or rhinorrhea, Battle's sign. Dangerous mechanism is a pedestrian struck by a motor vehicle, an occupant ejected from a motor vehicle, or a fall from an elevation of 3 or more feet or 5 stairs.

Figure 1. Canadian head CT rule.

Computed tomography is required for patients with minor head injury with any 1 of the following findings. The criteria apply only to patients who also have a Glasgow Coma Scale score of 15 .

1. Headache

2. Vomiting

3. Older than 60 years

4. Drug or alcohol intoxication

5. Persistent anterograde amnesia (deficits in short-term memory)

6. Visible trauma above the clavicle

7. Seizure

Figure 2. New Orleans criteria.

Hospital, Alnoor Specialist Hospital and Kind Faisal Hospital in Makkah, Saudi Arabia, from September 2015 to December 2015. The hospitals mentioned previously are the major emergency care hospitals in Makkah with state-of-art emergency practice.

\subsection{Study Design}

A self-reported based questionnaire was developed by the researchers through literature search (for validated questions), input from colleagues and from experts in the field of emergency medicine. The questionnaire was pretested on 10 participants (data not included in the results) before it was finalized.

The questionnaire was composed of three sections. First, it included demographic features of the candidate like age, gender, specialty and number of shifts per month. Second, the questions were focused on studying the physician's awareness of the management of TBI and head CT scan indications from their 
level of experience. Third, a clinical scenario of patient with mild head injury assesses the clinical judgment of the targeted physicians and it was focusing on the indication of head CT scan specifically. The case scenario was given to our participants about a minor head injury, which is a 23 -year-old male was playing football got struck to the temporal region with a ball during the game. He fell down to the ground with a brief 5 - 10 seconds loss of consciousness then he was helped up on his feet by other players. He was complaining of a headache, dizziness, and nausea without vomiting, and he could not recall the event of injury and he denied neck pain. He was brought to the emergency department for assessment. Primary survey was completely normal. The patient is alert, oriented and GCS is 15 but could not recall the event.

\subsection{Subject Selection}

The study involved 91 participants working as ED physicians at the above mentioned hospitals. The selection of participants was random by using simple numerical method (alphabetical).

\subsection{Data Analysis}

The data was entered on Statistical Package for Social Sciences (SPSS) version 21. Proportions were calculated for all variables of interest and chi-square test was used. A $p$-value of $<0.05$ was considered statistically significant throughout the study.

\section{Results}

The total study sample was 91 physicians working in ED. $76.92 \%$ of them were male (70) physicians of an age ranging from 28 - 55 years with a mean and standard deviation (SD) of $40.54 \pm 8.94$. Saudi nationality constituted around forty percents of study participants. Regarding experience of the participants, Twenty-three percent of study participants have less than two years of experience, while years of experience $3-5,6-10$ and more than 10 years were found in $37.6 \%, 15.3 \%$ and $24.7 \%$ respectively. It is clear that more than half of the physicians had 5 years of experience or less. Our data also showed that $55.3 \%$ of our participants are residents while specialists and consultants are $34.1 \%$ and $10.6 \%$ ) respectively. Upon our participants' hospital distributions, 32\% worked in Al-Noor Specialist Hospital, 9.9\% work in King Faisal Hospital, 19.8\% work in King Abdul Aziz Hospital while in Hera Hospital only 6.6\% of EPs had worked there during the study period. In regards to the level of qualification, Fifty-five percent of participants were residents while ER specialists represented $34 \%$ of total participants. Only 10 Consultants participated in the study, which means only eleven percents. It was though that the physicians taking more shifts would have more knowledge of the indications of head CT scan in TBI. Twenty-five percent of participants used to take more than 26 shifts per month, 33 participants used to take 23 - 26 shifts per month. Forty percent of participants used to 
take less than 22 shifts per month. He is complaining of mild headache and nausea. About $54 \%$ of our participants answered our question as minor head injury, $36.7 \%$ answered that the case as a moderate head injury, $7.8 \%$ described the case as severe head injury while $1.1 \%$ described it a massive head injury. Regarding the management for this patient, $24 \%$ of our participants would admit this patient for observation while $63.7 \%$ would order head CT scan. About 5\% would consult a neurosurgeon and lastly $6.6 \%$ would discharge the patient with instructions. Regarding exposure to trauma patients, $45 \%$ of our participants are used to see less than 10 patients suffering from head injury per month, $13.5 \%$ are used to see between 10 - 15 cases of head injuries while $41.6 \%$ are used to see 15 cases or more of head injuries per month. About the question "how frequent would you request head CT scan in case of trauma patients", the answers were as follow: $5.5 \%$ of them will always request head CT scan, $23 \%$ mostly request, $18.7 \%$ sometimes request and $4.4 \%$ rarely request head CT scan for trauma patients. Almost half of the participants will request head CT scan whenever they suspect head injury. Our EPs were asked whether they have ever heard about any clinical decision rules for minor head trauma or not. 54\% had answered yes while $45.6 \%$ had answered no. For those who answered with yes, they were also asked what clinical decision rule they are using. Most commonly used guideline was Canadian CT Head Rule in more than $42 \%$. Second most common used rule was CT in Head Injury Patients (CHIP). Interestingly, almost 19\% indicates that they are using their own experience. The application of any clinical decision rule was assessed in our survey and the result showed that $43 \%$ of our participants are always applying clinical decision rule into their practice and $44 \%$ most of the times. When we assessed knowledge and practice, majority were weak with $50 \%$ and $65 \%$ respectively (Table 1 ). By using Chi-square t-test, there were statistically significant differences between knowledge and sex, nationality, years of experience, duty load, field of interest and highest academic qualifications (Table 2). In contrast, practice was statistically significant with sexes and nationality $(p=$

Table 1 . More than $50 \%$ of participants were weak in both knowledge and practice.

\begin{tabular}{|c|c|c|}
\hline \multicolumn{2}{|c|}{ Knowledge } & \multirow[b]{2}{*}{50.55} \\
\hline Weak & 46 & \\
\hline Average & 31 & 34.07 \\
\hline Good & 14 & 15.38 \\
\hline Range & \multicolumn{2}{|c|}{$1-7$} \\
\hline Mean \pm SD & \multicolumn{2}{|c|}{$4.439 \pm 1.087$} \\
\hline \multicolumn{2}{|c|}{ Practices } & \\
\hline Weak & 59 & 64.84 \\
\hline Average & 18 & 19.78 \\
\hline Good & 14 & 15.38 \\
\hline Range & \multicolumn{2}{|c|}{$10-42$} \\
\hline Mean \pm SD & \multicolumn{2}{|c|}{$27.109 \pm 7.5813$} \\
\hline
\end{tabular}


Table 2. Descriptive statistical analysis of study variables versus knowledge.

\begin{tabular}{|c|c|c|c|c|c|c|}
\hline & & & & & ledge & \\
\hline & & & Mean & \pm & SD & $\mathrm{P}$-value \\
\hline Sour & Female & 21 & 4.857 & \pm & 0.573 & $0005-2>$ \\
\hline & Male & 70 & 4.314 & \pm & 1.174 & \\
\hline Notionolitor & Saudi & 36 & 4.750 & \pm & 0.937 & 0001 \\
\hline Nationanty & Non-Saudi & 55 & 4.236 & \pm & 1.138 & 0.021 \\
\hline & $0-2$. & 21 & 3.048 & \pm & 0.590 & \\
\hline Years of & $3-5$. & 29 & 4.103 & \pm & 0.310 & \\
\hline experience as EPs & $6-10$ & 18 & 5.000 & \pm & 0.215 & 0.000 \\
\hline & $>10$ & 23 & 5.696 & \pm & 0.703 & \\
\hline & $<18$ & 21 & 3.333 & \pm & 0.796 & \\
\hline Chifts no month & $18-22$ & 29 & 4.069 & \pm & 0.651 & 0000 \\
\hline & $23-26$ & 18 & 5.167 & \pm & 0.857 & 0.000 \\
\hline & $>26$ & 23 & 5.348 & \pm & 0.714 & \\
\hline & Surgical & 27 & 5.444 & \pm & 0.892 & \\
\hline Field of Interest & Trauma & 22 & 4.818 & \pm & 0.395 & 0.000 \\
\hline & Medical & 42 & 3.595 & \pm & 0.734 & \\
\hline & Resident & 50 & 3.880 & \pm & 0.895 & \\
\hline $\begin{array}{l}\text { Highest Academic } \\
\text { Qualification }\end{array}$ & Specialist & 31 & 4.742 & \pm & 0.631 & 0.000 \\
\hline & Consultant & 10 & 6.300 & \pm & 0.483 & \\
\hline
\end{tabular}

$0.135,0.248)$ respectively, while other factors did not show any significant relations (Table 3). In our study, the awareness and utilization rate of clinical decision rules between ER physicians were $54.4 \%$ and $42.2 \%$ respectively, while $45.6 \%$ of ER physicians are unaware of any clinical decision rules. However, $91.1 \%$ of those physicians would like to receive guidance on how to learn more about one of these guidelines. Our scenario supports our findings.

\section{Discussion}

In our study, $54 \%$ of participants diagnosed the patient in the scenario as cases of minor head trauma while the remaining half; their diagnosis was moderate to massive head trauma. So, the definition of minor head trauma is not cleared and understandable among some ER physicians. This means that almost 50\% patients with minor head injury will get head CT scan unnecessarily. There are two important studies previously published looking at the same issue. The first one was conducted among ER physicians. Its aim was to test physicians' awareness and use of the Canadian computed tomography head rule internationally in Canada, Australia, United Kingdom and United States of America in 2008 [10]. The second survey was to evaluate the awareness and use of the Canadian computed tomography head rule for mild head injury patients among Chinese emergency physicians in 2013 [5]. 
Table 3. Descriptive statistical analysis of study variables versus practice.

\begin{tabular}{|c|c|c|c|c|c|c|}
\hline & & \multirow{2}{*}{$\mathbf{N}$} & \multicolumn{3}{|c|}{ Practices } & \multirow[b]{2}{*}{$P$-value } \\
\hline & & & Mean & \pm & SD & \\
\hline \multirow{2}{*}{ Sex } & Female & 21 & 29.286 & \pm & 5.255 & 0.135 \\
\hline & Male & 70 & 26.457 & \pm & 8.068 & \\
\hline \multirow{2}{*}{ Nationality } & Saudi & 36 & 28.250 & \pm & 7.089 & 0.248 \\
\hline & Non-Saudi & 55 & 26.364 & \pm & 7.861 & \\
\hline \multirow{4}{*}{$\begin{array}{c}\text { Years of experience } \\
\text { as EPs }\end{array}$} & $0-2$ & 21 & 19.571 & \pm & 7.332 & 0.0001 \\
\hline & $3-5$ & 29 & 24.724 & \pm & 4.391 & \\
\hline & $6-10$ & 18 & 29.833 & \pm & 2.550 & \\
\hline & $>10$ & 23 & 34.870 & \pm & 5.093 & \\
\hline \multirow{4}{*}{ Shifts per month } & $<18$ & 21 & 21.762 & \pm & 7.543 & 0.0001 \\
\hline & $18-22$ & 29 & 24.138 & \pm & 5.680 & \\
\hline & $23-26$ & 18 & 31.833 & \pm & 6.582 & \\
\hline & $>26$ & 23 & 32.043 & \pm & 5.121 & \\
\hline \multirow{3}{*}{ Field of Interest } & Surgical & 27 & 33.296 & \pm & 6.299 & 0.0002 \\
\hline & Trauma & 22 & 29.091 & \pm & 3.650 & \\
\hline & Medical & 42 & 22.095 & \pm & 6.412 & \\
\hline \multirow{3}{*}{$\begin{array}{c}\text { Highest Academic } \\
\text { Qualification }\end{array}$} & Resident & 50 & 23.580 & \pm & 6.630 & 0.00067 \\
\hline & Specialist & 31 & 29.032 & \pm & 5.307 & \\
\hline & Consultant & 10 & 38.800 & \pm & 2.781 & \\
\hline
\end{tabular}

When we compared our survey with the above-mentioned studies, we found that there are discrepancies and varieties between our result and the other studies (Table 4). In survey from China, fear of malpractice was the leading obstacle for the use of CCHR by $48.5 \%$, followed by "pressure from administration to order more examinations" and "lack of knowledge about the radiation risk of CT", which were $29.5 \%$ and $27 \%$ respectively. In our study, the two most common limiting factors were the working environment and the possible increases in the risk of lawsuits by $55.4 \%$ and $61.7 \%$ respectively. However, $90 \%$ of our respondents believe that by utilizing the rules, there will be an improved usage of resources and patients will gain more benefits. Since the physician-patients relationship getting increasingly difficult, ordering CT scans for minor diseases is not uncommon practice [11]. That would explain the increasing numbers of head CT scans requested for minor head trauma as to confront patients and to avoid malpractice. In some setting, defensive medicine accounts for 1 out of 5 examinations [12]. The international survey conclude that the awareness of CCHR was highest in Canada and lowest in United States and that would be explained by the application of different rules as "it is the most commonly cited reason" [10]. For instance, most of physicians who participate in the survey from United Kingdom are using National Institute for Clinical Excellence (NICE).

\section{Conclusion}

Our survey showed that there is a misunderstanding of the definition of minor 
Table 4. Comparison between or study and the Chinese [5] and International [10] studies.

\begin{tabular}{cccccccc}
\hline & Our survey & $\begin{array}{c}\text { The Chinese } \\
\text { survey }\end{array}$ & \multicolumn{4}{c}{ The international survey } \\
\hline Male gender & $77 \%$ & $70.9 \%$ & \multicolumn{4}{c}{$71 \%$} \\
Awareness of CCHR & $54.4 \%$ & $41.7 \%$ & USA & AU & UK & CA \\
& & & $31 \%$ & $82 \%$ & $66 \%$ & $86 \%$ \\
Utilization rate & $42.2 \%$ & $24.7 \%$ & $12 \%$ & $32 \%$ & $21 \%$ & $57 \%$ \\
\hline
\end{tabular}

head injury, which led to request more CT scans despite head injury being one of the most common system involved in trauma. This will be a burden on the healthcare system and will lead to more radiation exposure. Our study also showed that working environment makes utilization of head CT rules difficult to follow and would increase numbers of lawsuits. These two factors are considered limiting reason for not applying the commonly used guidelines in minor head injury. Definitely, extra educational efforts should be conducted to improve the utilization of resources, reduce risk of radiation and DO NO harm to patients.

\section{Limitations}

There are some limitations to this study. Sample size was small with few numbers of consultants. We believe it should be a national survey to get better valid results.

\section{References}

[1] Faul, M., Xu, L., Wald, M.M. and Coronado, V.G. (2010) Traumatic Brain Injury in the United States: Emergency Department Visits, Hospitalizations and Deaths 2002-2006. Centers for Disease Control and Prevention, National Center for Injury Prevention and Control, Atlanta.

[2] Stiell, I.G., Wells, G.A. and Vandemheen, K. (2001) The Canadian CT Head Rule for Patients with Minor Head Injury. Lancet, 357, 1391-1396. https://doi.org/10.1016/S0140-6736(00)04561-X

[3] Galbraith, S. (1976) Misdiagnosis and Delayed Diagnosis in Traumatic Intracranial Haematoma. BMJ, 1, 1438-1449. https://doi.org/10.1136/bmj.1.6023.1438

[4] Larson, D.B., Johnson, L.W. and Schnell, B.M. (2011) National Trends in CT Use in the Emergency Department: 1995-2007. Radiology, 258, 164-173. https://doi.org/10.1148/radiol.10100640

[5] Huang, X., Zhou, J.C., Pan, K.H. and Zhao, H.C. (2013) Awareness and Use of the Canadian Computed Tomography Head Rule for Mild Head Injury Patients among Chinese Emergency Physicians. Pakistan Journal of Medical Sciences, 29, 951-956. https://doi.org/10.12669/pjms.294.3469

[6] Miller, E.C., Derlet, R.W. and Kinser, D. (1996) Minor Head Trauma: Is Computed Tomography Always Necessary? Annals of Emergency Medicine, 27, 290-294. https://doi.org/10.1016/S0196-0644(96)70261-5

[7] Jeret, J.S., Mandell, M., Anziska, B., et al. (1993) Clinical Predictors of Abnormality Disclosed by Computed Tomography after Mild Head Trauma. Neurosurgery, 32 
9-15. https://doi.org/10.1227/00006123-199301000-00002

[8] Haydel, M.J. (2005) Clinical Decision Instruments for CT Scanning in Minor Head Injury. JAMA, 294, 1551-1553. https://doi.org/10.1001/jama.294.12.1551

[9] Stiell, I.G., Clement, C., Rowe, B.H., et al. (2005) Comparison of the Canadian CT Head Rule and the New Orleans Criteria in Patients with Minor Head Injury. JAMA, 294, 1115-1518. https://doi.org/10.1001/jama.294.12.1511

[10] Eagles, D., Stiell, I.G. and Clement, C.M. (2008) International Survey of Emergency Physicians' Awareness and Use of the Canadian Cervical-Spine Rule and the Canadian Computed Tomography Head Rule. Academic Emergency Medicine, 15, $1256-$ 1261. https://doi.org/10.1111/j.1553-2712.2008.00265.x

[11] Wong, A.C., Kowalenko, T. and Roahen-Harrison, S. (2011) A Survey of Emergency Physicians' Fear of Malpractice and Its Association with the Decision to Order Computed Tomography Scans for Children with Minor Head Trauma. Pediatric Emergency Care, 27, 182-185. https://doi.org/10.1097/PEC.0b013e31820d64f7

[12] Swensen, S.J. (2012) Patient-Centered Imaging. American Journal of Medicine, 125, 115-117. https://doi.org/10.1016/j.amjmed.2011.06.002

Submit or recommend next manuscript to SCIRP and we will provide best service for you:

Accepting pre-submission inquiries through Email, Facebook, LinkedIn, Twitter, etc. A wide selection of journals (inclusive of 9 subjects, more than 200 journals)

Providing 24-hour high-quality service

User-friendly online submission system

Fair and swift peer-review system

Efficient typesetting and proofreading procedure

Display of the result of downloads and visits, as well as the number of cited articles

Maximum dissemination of your research work

Submit your manuscript at: http://papersubmission.scirp.org/

Or contact ojem@scirp.org 